\title{
LA MEDIACIÓN PENAL EN ITALIA ENTRE RESISTENCIAS CULTURALES, HERENCIAS INQUISIDORAS Y RESPETO POR LAS GARANTÍAS FUNDAMENTALES
}

The criminal mediation in Italy, between cultural resistances, inquisitorial claims and respect for fundamental rights

\author{
GASPARE DALIA ${ }^{1}$ \\ Universidad de Salerno
}

\section{RESUMEN}

\begin{abstract}
En nuestro país, como en otros en la Unión Europea, ha existido en los últimos años mucha atención por la justicia restaurativa, que puede definirse como una posible respuesta al crimen que involucra a su autor ydirecta o indirectamente- a la comunidad y/o a la víctima, en la búsqueda de posibles soluciones a los efectos del crimen, teniendo la concreta perspectiva de reparar sus consecuencias nocivas. La mediación es una de las formas más emblemáticas de justicia restaurativa, y es definida por la Recomendación 19 (99) del Consejo de Europa como "cualquier proceso que permite a la víctima y al reo participar activamente, si lo consintieran libremente, en la solución de las dificultades ocasionadas por el delito con la ayuda de un tercero independiente (el mediador)". El presente artículo analiza en clave crítica y sistemática las opciones legislativas que han afectado al sistema procesal penal italiano. También pretende verificar los posibles usos de esta forma de A.D.R. en pleno cumplimiento del actual sistema de proceso penal y las garantías fundamentales del acusado.
\end{abstract}

\section{PALABRAS CLAVE}

Mediación penal, garantías fundamentales, justicia restaurativa.

\section{ABSTRACT}

In our country, like in other ones in the European Union, the issue of restorative justice has recently drawn public attention; it may be defined as the possible solution to a crime that involves the offender and - directly or indirectly - the community and/or the victim, aiming to repair the effects of the offense. Defined as "any process whereby the victim and the offender are enabled, if they freely consent, to participate actively in the resolution of matters arising from the crime through the help of an impartial third party (mediator)" (Appendix to Recommendation No. R (99) 19 of the Council of Europe), mediation is one of the prime examples of restorative justice. The lecture analyzes the legislative choices recently adopted in the Italian criminal system in a critical way, also in order to verify the possible uses of this form of A.D.R. in full compliance with the current criminal trial system and the fundamental guarantees of the accused.

\section{KEYWORDS}

Criminal mediation; fundamental rights; restorative justice

\section{Premisa: la mediación para contribuir a la eficiencia de la justicia penal}

Desde la antigüedad, los hombres han desarrollado dos formas de reparación de los delitos: el sacrificio (como reparación por aquellos hechos que convulsionaban tan profundamente la vida de la comunidad que temían que pudieran cuestionar la protección de las deidades) y la venganza (por aquellos hechos que cuestionaban las relaciones entre familias y clanes en una época en la que el individuo solo importaba como parte de un grupo).

${ }^{1}$ Investigador de Derecho Procesal y Profesor de Derecho Procesal Comparado en la Universidad de Salerno, Salerno, Italia. Este artículo es el resultado de la síntesis, con modificaciones, adiciones y actualizaciones, de los informes realizados en el contexto del I y $1 /$ Congreso Internacional sobre sistemas procesales penales y mediación, que tuvo lugar en la Universidad de Salamanca del 18 al 19 de octubre de 2012 y en los días 21-22 de noviembre de 2013. Correo electrónico: gadalia@unisa.it. 
En el último siglo y medio, la pena -expiada mediante la privación de libertad y todas sus alternativas- se ha entendido como la reeducación del responsable, mientras que en los últimos treinta años se ha redescubierto la modalidad reparadora de la pena para el beneficio del ofendido, depurada -obviamente- del antiguo origen de autotutela.

Estos cambios en la justicia penal, especialmente la justicia de menores, no habrían tenido mucho impacto si las instituciones penales no hubieran entrado en un estado de profunda crisis debido al crecimiento exponencial de los litigios. Si bien los defensores de la mediación y la justicia restaurativa siempre han argumentado que sus propuestas no tenían intenciones deflacionistas, las instituciones las han tomado en consideración casi exclusivamente para este propósito.

Especialmente en el mundo anglosajón, en sus primeras aplicaciones, la justicia restaurativa se expresó a través de prácticas, ensayos experimentales e iniciativas locales sin el apoyo de bases normativas y sin inversiones institucionales, en pleno cumplimiento del enfoque empírico que posee la cultura, también la cultura jurídica, de los países de ultramar².

Entre finales de los años 80 y principios de los 90 del siglo XX, se manifestó en Europa la necesidad de reconocer las experiencias de la justicia restaurativa en el ámbito penal, y sobre todo de la mediación autor-víctima, a través de la normativa destinada principalmente a la justicia penal juvenil, a lo que contribuyó el impulso de los criminólogos que asumieron un verdadero modelo alternativo de justicia penal llamado a enfrentarse a los modelos de retribución y reeducación ${ }^{3}$.

Por lo tanto, se ha depositado mucha confianza en la mediación como mecanismo para ayudar a resolver el problema primordial de la administración de la justicia penal. La institución de la justicia restaurativa podría servir de vehículo para difundir la cultura de la mediación, aunque sin reemplazar la justicia del Estado con una especie de justicia privada.

Las razones para el desarrollo de dicho modelo son identificables tanto en la crisis de los tradicionales fines de la pena (retribución y rehabilitación) como en la necesidad de considerar a la víctima como una parte importante, y no marginal, del crimen cometido y, en consecuencia, de todo el proceso penal, que está destinado a ser una herramienta para la correcta y legal averiguación del hecho, de manera que afecte a todas las partes involucradas. El esquema restaurativo permite, de hecho, condensar el conflicto a través del desarrollo de programas de mediación entre la víctima y el delincuente con el objetivo de buscar un acuerdo para reparar los daños derivados del delito, de manera que sea satisfactorio para los intereses de ambos y, al mismo tiempo, proporcione resultados útiles también para la reeducación del delincuente.

Lamentablemente, nuestro país no se ha mostrado en el pasado preparado para el desarrollo de una conciencia cultural en la dirección de la protección total de la víctima, ni social ni políticamente, dado que la estigmatización del delincuente no prestaba protección adecuada de la víctima ${ }^{4}$. La doctrina procesal penal siempre se ha centrado por completo en la

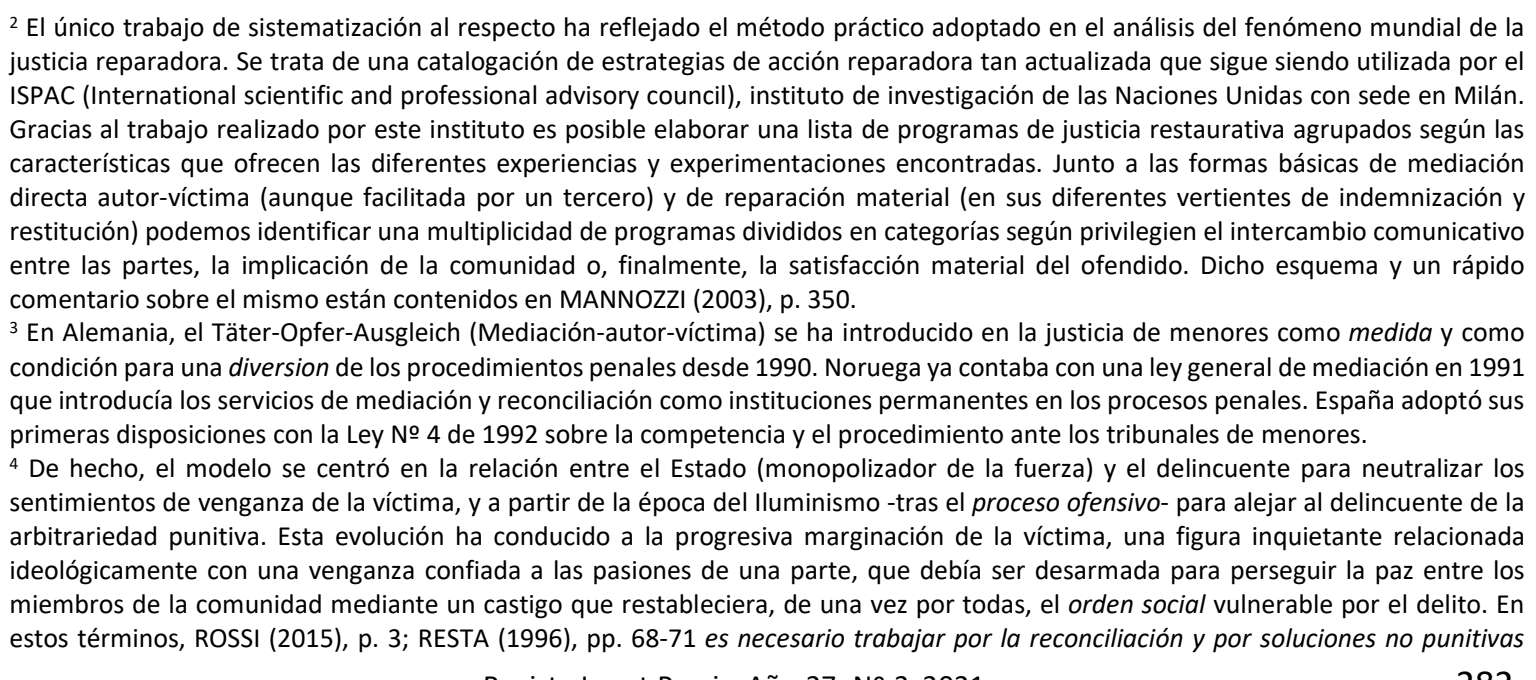


idea de que el proceso penal debe ser un instrumento de garantía para el acusado y solo para el acusado 5 .

El logro del objetivo tan deseado del juicio justo para el acusado, quizás parecía cuestionado por el reconocimiento a la víctima de un papel que, por razones culturales, habría sido visto como una deminutio de las garantías del sospechoso/acusado, ya bastante perjudicado por la investigación criminal, que se basada más en la vieja lógica inquisitorial que en las concepciones modernas, básicamente acusatorias.

Como se ha observado correctamente, el cambio progresivo de un modelo penal inspirado en la idea del delito como un crimen contra la sociedad (es decir, contra los activos legales de la comunidad) a una concepción del mismo como un crimen contra las víctimas y las comunidades a las que pertenecen inmediatamente (...) debe apreciarse como un efecto de la reconversión gradual, a nivel interpretativo, del delito de violación de las reglas del sistema a la lesión de víctimas concretas; $y$, más generalmente, del cambio en la concepción individualista-normativa de la persona ${ }^{6}$.

Sin embargo, el impulso supranacional finalmente ha marcado el ritmo y ha sido necesario ofrecer al ofendido/víctima un reconocimiento adecuado y una mayor legitimidad para actuar en términos de protección contra conductas que, particularmente en la delincuencia de género, han resultado difíciles de controlar ${ }^{7}$. Esto se debe a que un enfoque más específicamente dirigido a la víctima como persona activa (y portadora de derechos, decisiones y necesidades) debe hacer que la victimología se entienda como una disciplina que posee su estatuto epistemológico, así como una metodología orientada a detectar causas, condiciones y procesos victimizantes primarios y secundarios ${ }^{8}$.

La mediación también parece tener como objetivo promover una mayor responsabilidad de todas las partes -que a menudo una sanción penal tradicional no puede garantizar- para reducir el riesgo de victimización y tratar de aliviar, en la medida de lo posible, el sufrimiento psicológico y emocional infligido al ofendido.

Por lo tanto, el tema de la mediación es central en el campo comparativo, y es útil trazar sus contornos para contribuir concretamente a la creación de ese espacio de libertad, seguridad y justicia que la Unión Europea espera de todos los estados miembros, más aún a través de comparación con otras realidades no europeas, como la de Argentina, que ya ha introducido con éxito la institución de la mediación penal en su sistema judicial.

Sin embargo, incluso reconociendo una necesidad creciente de garantizar el libre acceso a la tutela que se debe a todo ciudadano -como por ejemplo el derecho de apelar ante el juez para la protección de los derechos y intereses legítimos de conformidad con el art. 24 de la Constitución italiana-, cuando se propone cualquier reforma es aconsejable ser cauteloso, ya que es necesario un enfoque sistemático.

Al adoptar las elecciones de política penal necesarias, los legisladores nacionales nunca pueden ignorar el principio del debido proceso, garantizando por ello el concepto de debido acceso a un sistema de justicia más eficiente.

dentro de la comunidad y pensar en términos de un código afectivo, aunque antes y fuera del código de la ley, sobre la idea de que la confianza [...] no puede insertarse en contextos de estrategias punitivas.

${ }^{5}$ En estos términos, TRANCHINA (2010), p. 4051B, que también subrayó que una exclusión de la víctima del juicio podría haber llevado a un impulso para buscar justicia al margen de los tribunales, con un retorno a una especie de venganza privada anacrónica.

${ }^{6}$ Así CORNACCHIA (2013), p. 1764.

${ }^{7}$ Para un examen cuidadoso y la reconstrucción sistemática de fuentes supranacionales en el contexto europeo, ver SECHI (2017), p. 0850B. Como se ha argumentado excelentemente, Europa no reemplaza al Estado en la administración de justicia para el caso individual, sino que reconoce a los individuos una serie de derechos y dicta reglas de organización y funcionamiento dirigidas a los Estados. La novedad radica en la circunstancia de que fórmulas que no son más que recomendaciones y por tanto privadas de sanción, de manera imprevista han alcanzado carácter obligatorio y eferctiva validez. En la continua reforma de la Constitución, de las leyes y las aportaciones jurisprudenciales, el espíritu europeo se ha convertido en un factor de estímulo y entusiasmo inagotable en la aspiración de lograr un monitoreo constante y completo del estado actual de la llamada "norma real" (en el proceso penal, por supuesto), incluso más allá de los estrechos límites internos y los esquemas exegéticos tradicionales. Así GAITO (2015), p. 30. Ver, nuevamente, sobre el tema ALLEGREZZA (2012), p. 1-31; CASSIBBA (2017), p. 67; MARTELLI (2015), p. 32.

${ }^{8}$ Según ZARA (2018), p. 615, la víctima a menudo ha sido relegada a un papel de pasividad que durante mucho tiempo la ha convertido en sujeto pasivo de la justicia. 
Sin embargo, el fin no debe justificar los medios, porque en el caso de la mediación penal se trata de lidiar con delitos y castigos y, tal vez, con derechos no disponibles.

\section{Buscando alternativas al proceso}

Con esta premisa, también es importante no verse tentado por la urgencia de tener que encontrar soluciones absolutas, rápidas y aparentemente indoloras, a las deficiencias del sistema judicial, especialmente cuando esas soluciones no responden a las necesidades propias de la víctima del delito ${ }^{9}$. Y la preocupación aumenta si tales urgencias van a minar la estructura del sistema procesal penal actual, dado que existe para ofrecer las máximas garantías para las personas involucradas en el hecho de que debe averiguarse ante los tribunales.

La doctrina, al referirse al tema de las perspectivas de reforma de la ley procesal penal española, ha manifestado que siempre se debe preferir la construcción de un modelo de proceso ordinario que no comience desde situaciones de emergencia y, para lograr este objetivo, podemos y debemos utilizar la experiencia de otros países ${ }^{10}$.

Al estudiar las opciones legislativas en torno al uso de medios alternativos al proceso, debe destacarse que países como Italia, aunque revistieran de garantías los procesos penales, no por ello desdeñaron en modo alguno el uso de métodos alternativos para ejercer la función judicial. El Código de Procedimiento Penal italiano de 1988, además, hizo de algunos de sus principales procedimientos alternativos y modalidades alternativas de ejercicio de la acción penal su producto estrella, elevándolos a la categoría de mecanismos procesales capaces, por un lado, de garantizar una complejidad de tratamiento coherente con el desvalor del delito juzgado y, por otro lado, de mantener siempre con firmeza las garantías consideradas esenciales en un sistema tendencialmente acusatorio que fuera respetuoso con los principios constitucionales.

No obstante, debe decirse que las intervenciones legislativas posteriores han ampliado de manera tan significativa el alcance de la operatividad de esos mecanismos ${ }^{11}$, que han generado la percepción de que persiguen solo un objetivo deflacionario ${ }^{12}$ y que, por tanto se podrían arrinconar las modalidades ordinarias de jurisdicción, en parte como sucede en los tan frecuentemente imitados procesos estadounidenses ${ }^{13}$.

Entre tanto, el concepto de juicio justo también se ha constitucionalizado con la modificación del art. 111 de la Constitución ${ }^{14}$, cuyas garantías deben sin duda ser reconocidas a todos los sujetos involucrados en el proceso porque o dependen de él o, en cualquier caso, tienen interés en él: investigado/acusado, víctima, comunidad ${ }^{15}$.

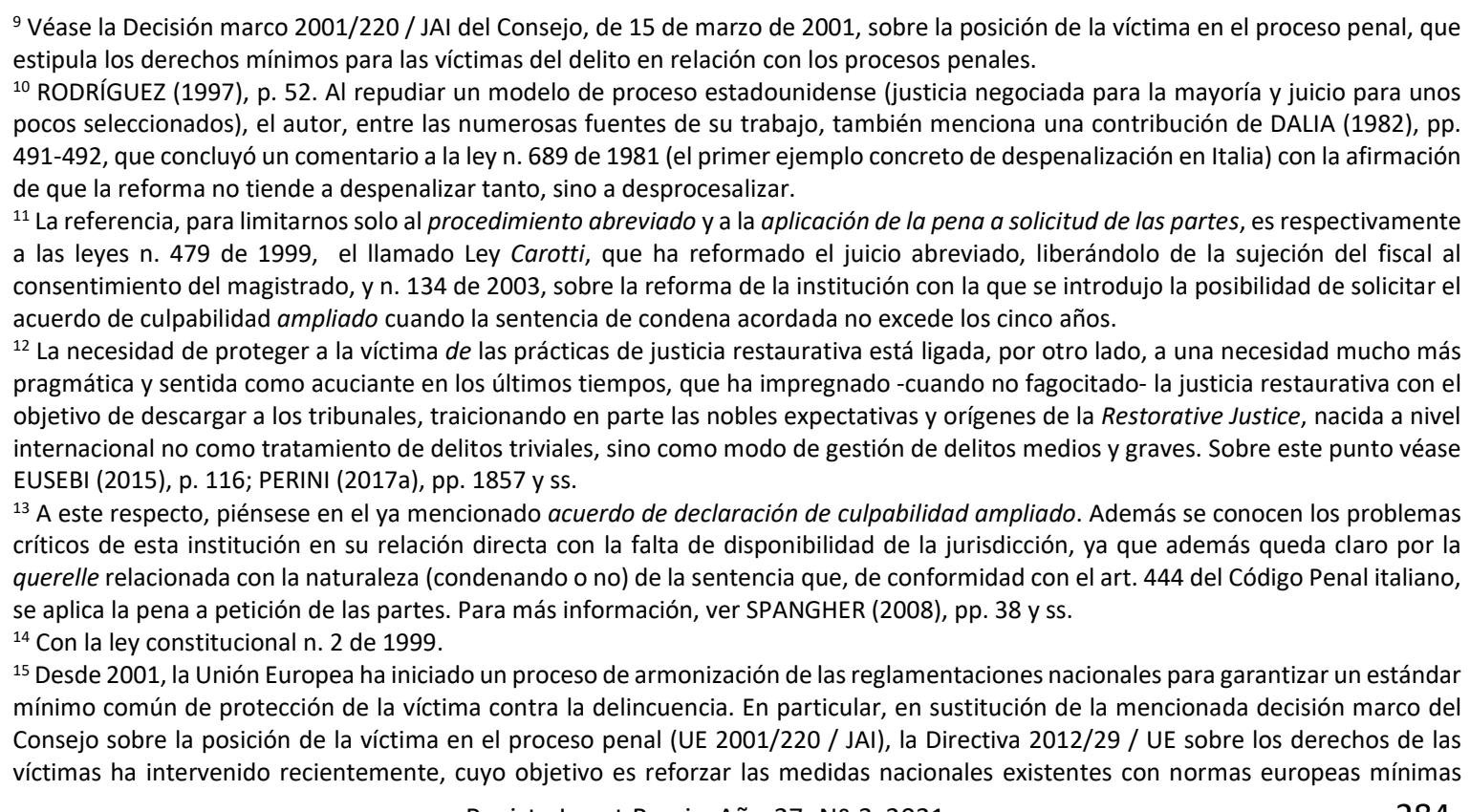


Por lo tanto, a fortiori, la simplificación, la velocidad y la efectividad del proceso penal son propósitos dignos de ser perseguidos y logrados, sin descuidar no obstante estas garantías fundamentales, que por lo tanto no deben ser prescindibles. Tampoco el objetivo de la velocidad debe lograrse exclusivamente a través de reformas procesales.

Solo una profunda reorganización de los presupuestos político-criminales que se reflejan de manera articulada y congruente en las diferentes fases del sistema penal (legislación sustantiva, procesal y penitenciaria) podrá conducir a una solución en el panorama actual. Esa reorganización también deberá dar garantías a los sujetos que, como víctimas del delito, tienen obviamente derecho a una reparación y compensación por daños.

\section{La predisposición del sistema procesal italiano a la mediación penal}

Un dato no menor es el siguiente: los juristas -abogados y jueces- son una fuerza impresionante en los países de la UE. Los últimos datos disponibles hablan de un "ejército" de 1.414.930 juristas, es decir, uno de cada 360 habitantes se dedica profesionalmente al derecho.

Esto significa que si los juristas formaran una alianza en nombre de los instrumentos alternativos, en al menos ocho países europeos los litigios de primera instancia podrían desaparecer en un año.

Sin embargo, la política no ha pensado en las ADR como una solución real con la debida atención, al menos en los tiempos modernos ${ }^{16}$, y en Europa estamos todavía muy lejos de pensar que la justicia necesita una ayuda de los medios alternativos ${ }^{17}$.

Parte de la responsabilidad es atribuible a la Unión Europea, que, aunque se ha inspirado en lo ocurrido en Estados Unidos y Gran Bretaña, a lo largo de los años ha tratado de mejorar el acceso al proceso principalmente en el ámbito civil. También ha impulsado una mediación voluntaria, alejada de la cultura jurídica europea y no sólo italiana, ya que al menos 25 estados de la UE -de los 27- tienen hoy en día al menos un instrumento obligatorio de mediación civil, mientras que sólo dos estados en Europa tienen instrumentos puramente voluntarios, a saber, Finlandia y Eslovaquia.

Todo esto no ha contribuido a lo largo de los años a crear conciencia sobre la institución de la mediación, aunque persisten a día de hoy al menos dos de esos problemas: el desconocimiento de la misma y la disparidad en la formación y calificación de los mediadores ${ }^{18}$.

Entonces: ¿Cuáles son los "espacios" para una mediación penal en Italia? Existe una instintiva desconfianza (casi total) por cualquier iniciativa -como la mediación penal- que pudiera contaminar la investigación del delito y, por lo tanto, el juicio penal como garantía de la

relativas a los derechos, el apoyo y la protección de las víctimas de delitos en cada país de la UE. El legislador italiano -con el Decreto Legislativo n. 212 de 5 de enero de 2016- no parece haber captado este impulso reformador, limitándose a dotar a la tradicional figura del ofendido de una serie de derechos y facultades más amplias que en el pasado, pero sin afectar a la filosofía básica del Código Procesal, casi con el temor de que una potenciación del papel de la víctima pueda impregnar de "emocionalidad" el proceso penal, haciendo más inestable el equilibrio de los delicados intereses que lo sustentan. Así, MUZZICA (2019), p. 9. Entre las diversas prerrogativas de información que, como hemos visto, acompañan al estatuto de la víctima, parecen dignas de especial mención las previstas en las letras $n$ y o del art. 90-bis c.p.p. Los propósitos que subyacen a esta nueva información son múltiples y se entrecruzan claramente con el complejo sistema de Restorative justice, del que la potenciación del papel de la víctima es, como es sabido, un verdadero rasgo característico. En estos términos PARISI (2015), pp. 123 y ss.

${ }^{16}$ Para apoyar a los tribunales, los ciudadanos de los 27 -hasta entonces 28- países de la UE gastaron per cápita en 2017 desde 30 euros en Chipre hasta 215 euros en Luxemburgo: Italia, que se encuentra en la posición media, pidió a los italianos 96 euros per capita. Un caso aparte es Finlandia, que invierte 7 millones de euros al año en la mediación familiar y en la penal. Sin embargo, en el resto de países se ha pretendido que los mediadores resuelvan los litigios sin coste alguno.

${ }^{17}$ El número de mediaciones conocidas en los 27 países de la UE constituye solo entre el 0,96 y el $1 \%$ de la pendencia en primera instancia (2017). Los acuerdos alcanzados en las mediaciones fueron solo el 0,14\% de la pendencia en primera instancia en 2017. Sinceramente, estamos a distancias siderales de lo prometido por el art. 1 de la Directiva 52/08, es decir, la garantía de una relación equilibrada entre la mediación y el procedimiento judicial. Si no fuera por Italia, cuyo número de mediaciones exitosas constituye, según datos de 2019, entre el 66 y el 68,76\% del total de mediaciones conocidas, la mediación sería probablemente hace tiempo un recuerdo lejano. En Italia se llegó a algún tipo de acuerdo en el 65,84\%, a pesar de que las mediaciones propias (147.691) supusieron sólo el $4,48 \%$ de la pendencia judicial de 2019 (3.293.960 asuntos; cifra de abril de 2020).

${ }^{18}$ Los datos nos dicen que solo un país (Finlandia) está bien encaminado, o al menos lo estaba en 2016, con una tasa del 17,51\%. Luego está Italia con un 4,48\% en 2019, Malta con un 4\% (aunque el dato es de 2013), Letonia en 2016 con un 2,99\% y Hungría en 2018 con un $2,12 \%$. Del resto de países, 7 están por debajo del $1 \%$ y sobre 14 naciones, entre ellas Francia, Alemania y Reino Unido, ni siquiera podemos dar información porque no publican sus datos. 
jurisdicción, de la que se espera y requiere un fortalecimiento cada vez mayor, a pesar de las numerosas, erráticas y descoordinadas intervenciones legislativas que, en materia de política criminal, parecen estar dirigidas cada vez más, en realidad, a una tendencia criticable hacia la desprocesalización.

Por lo tanto, incluso desde un punto de vista cultural parece prematuro hablar de mediación -y en particular de mediación penal en sentido estricto-, en un ámbito en el que el poder de reconocer una indemnización a la víctima se dejaría no sólo a un juez -máxima expresión de civilización que puede ofrecer un estado de derecho, ya que, con su función, expresa la más alta de las garantías, es decir, la de la jurisdicción-, sino a una persona privada que, aunque sea tercero e imparcial -y quizás "reconocido oficialmente" por las instituciones-, carece de función jurisdiccional.

De hecho, el mediador por antonomasia es diferente a un juez porque no juzga, no toma decisiones, sino que trata de mediar, de reconciliar a las partes separadas por un conflicto.

$Y$ para demostrar que las preocupaciones en este tema no son tan infundadas, basta referirse a cuanto sucedió en Italia en el campo de la mediación civil.

El legislador italiano implementó la directiva 2008/52, que con el Decreto Legislativo n. 28 de 2010 presentó las herramientas legales para la mediación en el sector civil y comercial ${ }^{19}$.

Las definiciones de mediación y mediador que aporta el art. 1 del Decreto Legislativo $\mathrm{n}$. 28 de 2010, parecen fundamentales para identificar las características de esta institución, distinguiéndola de otras figuras con analogías ya reguladas en el código civil y en el código procesal civil.

Los considerandos de la Directiva n. 2008/52 / CE del Parlamento Europeo y del Consejo de la Unión Europea ${ }^{20}$, describen el enfoque general del Reglamento en lo que respecta a sus propósitos y características, partiendo de la suposición de que, en primer lugar, la mediación es uno de los métodos de Alternative Dispute Resolution (ADR) (art. 1, sección 1, letra b), Decreto Legislativo n. 28 de 2010).

Aunque se configurara la institución de un modo tan simplificado, las primeras experiencias de aplicación de la mediación civil mostraron que fue un fracaso, con la consecuencia de que se generó en los operadores jurídicos -y también en la sociedad- la idea de que la institución se estaba traduciendo no sólo en una desprocesalización -entendida como sustracción de jurisdicción-, sino también en un negocio. Según la Comisión Europea, las opciones implementadas por el legislador italiano no estaban en línea con la búsqueda consensuada del acuerdo de mediación, ya que no se garantizaba el derecho a decidir libremente cuándo cerrar el proceso de mediación. En realidad el legislador favoreció un sistema en el que las partes, de hecho, se ven obligadas a aceptar la propuesta del mediador para evitar toparse con ciertas sanciones económicas ${ }^{21}$.

Esta elección legislativa ha demostrado la gran inconsistencia subyacente que impregna la mediación civil: la raíz semántica del término, de hecho, sugiere la idea de acercamiento mutuo a través de una reunión intermedia y, por lo tanto, requiere una libre elección de las partes al decidir hacer uso de esta herramienta. Está claro, por consiguiente, que la mediación es, podríamos decir, ontológicamente incompatible con la naturaleza obligatoria, lo que implica que cuando se impone esa naturaleza forzosa, se está falseando su propia esencia, comprometiendo así sus posibilidades de éxito.

\footnotetext{
${ }^{19}$ La disposición representa el instrumento con el cual el Gobierno implementa la delegación que le confiere el art. 60 de la ley n. 69 de 18 junio de 2009, que contiene Disposiciones para el desarrollo económico, la simplificación, la competitividad y los asuntos de juicio civil.

${ }^{20}$ De conformidad con la invitación hecha a los Estados miembros por el Consejo Europeo en la reunión de Tampere del 15 y 16 de octubre de 1999, las conclusiones adoptadas por el Consejo en mayo de 2000 sobre métodos alternativos de resolución de disputas en asuntos civiles y comerciales, así como el Libro Verde presentado por la Comisión en abril de 2002, relativa a formas alternativas de resolver disputas en los asuntos antes mencionados, Directiva 21 de mayo de 2008, n. 2008/52 / CE del Parlamento Europeo y del Consejo de la Unión Europea ha regulado algunos aspectos de la mediación en materia civil y mercantil.

${ }^{21}$ Además, el Tribunal Constitucional (sentencia n. 272 de 23 octubre de 2012) declaró la ilegitimidad del art. 5 de la ley de mediación civil, en el inciso que alude a una obligación de intentar la mediación, dado que se estableció que ese intento erauna condición de admisibilidad de la demanda Sin embargo, la regla no fue declarada inconstitucional porque la mediación fuera obligatoria, sino porque la ley del gobierno fue más allá de la delegación recibida del Parlamento.
} 


\section{Los precedentes de la mediación penal en Italia}

Hacia el final de los años 90 nació una comisión de estudio en el DAP (Departamento de Administración Penitenciaria) del Ministerio de Justicia, que puso en valor las indicaciones jurisprudenciales de los Tribunales de Vigilancia para impulsar programas de justicia restaurativa. Además, tuvo en cuenta lo que ya había madurado o se estaba desarrollando en el ámbito internacional, como por ejemplo la Declaración sobre Crimen y Justicia del X Congreso de la ONU (Viena, 10-17 de abril de 2000), que tenía como objetivo reducir la delincuencia a través del uso de medidas de justicia restaurativa.

La Resolución 15/02 del Consejo Económico y Social de la ONU también había propuesto una definición supranacional de justicia restaurativa, calificándola como aquel procedimiento en el que la víctima, el reo y cualesquiera otras personas o miembros de la comunidad afectados por un delito participen conjuntamente de forma activa en la resolución de cuestiones surgidas del delito, a menudo con la ayuda de un tercero justo e imparcial.

Todo ello implicó la confrontación con un problema: si las definiciones supranacionales afirman que la justicia restaurativa debe basarse en el libre consentimiento, donde la adhesión al proceso de mediación por parte del condenado se convierte en una prescripción a cumplir dentro del programa ejecutivo de la pena, la voluntariedad para adherirse puede quedar degradada en su significado.

La Comisión en el DAP estructuró programas de justicia restaurativa dentro de algunos institutos como, por ejemplo, el art. 165 del Código Penal sobre la suspensión condicional de la pena (que puede estar sujeta a una indemnización por daños o la reducción de las consecuencias nocivas y peligrosas del delito) o el art. 176 del Código Penal, que supedita la libertad condicional al cumplimiento de las obligaciones derivadas del delito y a comportamientos que demuestren un real arrepentimiento del condenado.

La fase de experimentación iniciada por la Comisión dio lugar a un número limitado de mediaciones penales. Y tal y como se solicitó, correspondió a los Tribunales de Vigilancia informar a la Comisión de los casos en los que proponer la mediación penal entre adultos. En los casos de menores, sin embargo, ya se había practicado desde hace algunos años.

La institucionalización de la mediación -y, en general, de las medidas restaurativas- ha marcado un cambio importante: de vía alternativa a la jurisdicción pasó a ser propuesta como medio de diversificación de la intervención de la justicia penal.

Pero la justicia restaurativa -especialmente en los sistemas que se rigen por el principio del ejercicio discrecional de la acción penal- no ha tenido, en consecuencia, un efecto deflacionista: al contrario, ha permitido que se tomen en consideración situaciones que, anteriormente, eran objeto de desestimación por parte del fiscal.

Por lo tanto, una mediación penal que desee inscribirse en esa línea pareciera estar basada en fundamentos bastante frágiles. Es cierto, además, que la normativa supranacional se encaminaba en otra dirección.

La Recomendación n. 19 (99) de 1999 del Consejo de Europa en materia de mediación penal, de hecho, proporcionó indicaciones claras e inequívocas: una de las piedras angulares de un buen sistema de mediación se encuentra en la participación espontánea en la misma, ya que la mediación en el campo penal solo debe llevarse a cabo si las partes acuerdan libremente participar (art. 1 Rec.). Además, las partes deben estar plenamente informadas de sus derechos, de la naturaleza del proceso de mediación y de las posibles consecuencias de sus acciones (art. 10 Rec.) Y no deben ser inducidas a participar en la mediación a través de subterfugios (medios injustos, art. 11 Rec.). Por esta razón, la mediación no es posible si una de las dos partes no comprende completamente su significado (art. 13 Rec.).

Finalmente, otro principio estrictamente relacionado con la libre participación es el de la confidencialidad de la información y de los contenidos de la mediación (excepto el acuerdo final, si se alcanza) (art. 2 Rec.). 
Sin embargo, también es cierto que en Italia, desafortunadamente, existe un sistema potencialmente incompatible con la mediación penal. Véase que el código procesal italiano indica que el perdón del ofendido no puede ser sometido a condición ${ }^{22}$, al tiempo que se incentiva la justicia restaurativa premiando al reo en el marco de la imposición de una sanción que, en cualquier caso, debe imponerse con el fin de reconocer las circunstancias atenuantes y favorecer el procedimiento de rehabilitación.

Además de la experiencia de la mediación civil, existen otras razones que invitan a la cautela en este campo. Los ejemplos de mediación penal en el sistema legal interno se han desarrollado, como se ha mencionado, en la justicia juvenil y ante el juez de paz.

La experiencia de este último ha fallado porque el juez de paz no tiene poderes efectivos para conciliar, a pesar de que su denominación implica que la conciliación, la paz, debería ser el objetivo máximo a perseguir ${ }^{23}$. En cambio, en los procedimientos de menores la situación es bastante diferente. Nos enfrentamos a una disciplina vanguardista ya que, al menos en esto, nuestro legislador ha demostrado ser particularmente sensible a los problemas del mundo del menor, situándose en una posición extremadamente garantista. En este contexto, es fácil imaginar, por un lado, cuán estrechos pueden ser los espacios reservados para la víctima/ofendido; pero por el otro, apreciamos algunas formas de mediación "no convencional", cuyas peculiaridades están conectadas precisamente con las especificidades del procedimiento penal juvenil. En particular debe leerse el art. 28 del Decreto presidencial n. 448 de 1988 (Código de Juicio Juvenil), cuya segunda sección establece que con el auto de suspensión, el juez encomienda al menor a los servicios de menores de la administración de justicia para la realización, también en colaboración con los servicios locales, de las correspondientes actividades de observación, tratamiento y apoyo. En la misma resolución el juez puede emitir instrucciones directas para remediar las consecuencias del delito y promover la conciliación del menor con el ofendido.

Por lo tanto, el recurso al instrumento particular de la suspensión condicional del juicio sometiendo a prueba al menor, incluye una forma de justicia restaurativa ya que, de hecho, la realización de actividades destinadas a reparar el daño y reconciliarse con el ofendido no son el resultado de una voluntaria decisión del menor acusado por el delito, sino una instrucción impartida por el juez para que pueda decirse que ha pasado la prueba a la que está sometido el acusado.

Sin embargo, de lo indicado se destacan dos peculiaridades. En primer lugar, se trata de una herramienta reguladora que se basa en una indisimulada asimetría de planos: el menor no admite completamente su culpabilidad, pero se pone a disposición para llevar a cabo actividades destinadas a mitigar o reparar daños de los cuales, evidentemente, se cree responsable "informalmente". En segundo lugar, debe considerarse que, independientemente del resultado del intento de conciliación con la víctima, siempre es el juez quien determina si teniendo en cuenta el comportamiento del menor y la evolución de su personalidad, la prueba ha dado resultados positivos, en cuyo caso declara el delito extinguido por sentencia. Por tanto, se trata de una forma de mediación ${ }^{24}$ completamente atípica, en la cual los intereses de la víctima

\footnotetext{
22 De hecho, debe subrayarse que la disposición tradicional contenida en el art. 152 del Código Penal - según el cual la remisión es procesal [art. 340 c.p.p.] o extrajudicial. La remisión extrajudicial es expresa o tácita. Hay una remisión tácita, cuando el demandante ha cometido los hechos incompatibles con la voluntad de persistir en el caso - está sujeto a una excepción singular introducida por la sección 4 del art. 612 bis del Código Penal italiano con ley n. 119 de 15 de octubre de 2013 (la llamada ley de "feminicidio"), con la cual el legislador ordenó que el aplazamiento de la solicitud solo pueda ser procesal. Sin embargo, no se puede decir que la intervención fue completamente incorrecta: la Corte Suprema, de hecho, con la sentencia n. 2301 presentada el 16 de enero de 2015, declaró que la remisión del caso presentada ante un oficial de la policía judicial debería considerarse una remisión procesal, con un evidente debilitamiento de las estrictas solicitudes del legislador.

${ }^{23}$ De hecho, el procedimiento afecta claramente la duración razonable, ya que el aplazamiento de la audiencia, de hecho ex officio, solo para llevar a cabo el intento obligatorio de conciliación no hace más que alargar el tiempo de la investigación.

${ }^{24}$ En un sentido más amplio, debe decirse que se puede criticar la confusión de planos entre la justicia restaurativa y la mediación. Ver SCARDACCIONE (1997), p. 10. Por el contrario, ver RIONDINO (2009), pp. 447- 466 según el cual la mediación trata de redescubrir la verdad, al culpable y a la víctima, en términos de relevancia relacional", buscando un proceso dinámico dentro del cual se crea una confrontación de empoderamiento maduro también referido a valores éticos. Por esta razón, la mediación es una de las manifestaciones más concretas de la justicia restaurativa.
} 
adquieren una marcada importancia colateral; la conducta restaurativa y los intentos de "reconciliación" son utilizables simplemente como indicadores de un resultado positivo de la prueba, por lo que el centro de la institución es el menor, no la víctima. Además, si consideramos la posibilidad de iniciar un proceso de reeducación, acompañado de instrucciones conductuales particularmente aflictivas incluso antes de determinar por sentencia la responsabilidad penal del acusado, la probation procesal a que se refiere el artículo 28 del Decreto Presidencial n. 488 de 1988 plantea nuevas dudas sobre la coherencia sistemática con respecto a la compatibilidad de esta institución con la presunción de inocencia, de conformidad con el art. 27 de la Constitución. Aunque en el plano teórico la problemática no pueda darse por solventada, la institución en cuestión no ha recibido censuras por parte de los jueces, tal vez en consideración del deber de la República de proteger a los niños y jóvenes, favoreciendo las instituciones necesarias para dicho propósito (Art. 31, párrafo 2 de la Constitución).

Además, el legislador de 2014 no se planteó avanzar en este camino de reconciliación entre acusado y víctima, extendiendo a los adultos la institución de la suspensión del juicio con la puesta a prueba del reo ${ }^{25}$.

Con esta institución, desde mayo de 2014 la mediación penal se ha convertido en una realidad y ha encontrado su aplicabilidad por primera vez en la fase preliminar. El garante de la ejecución del programa de libertad condicional es la Oficina de Ejecución Penal Externa (UEPE), es decir, los trabajadores sociales de la UEPE. Si la mediación con la víctima forma parte del programa de libertad condicional, se remitirá el caso a un centro de mediación. No hay formalidades establecidas específicamente por el legislador.

Posteriormente, el mediador informa al UEPE emisor solo si la mediación tuvo lugar o no. Preliminarmente se realizarán entrevistas individuales con cada sujeto, que podrán o no conducir a la reunión de mediación. Si la víctima, por ejemplo, no participa en entrevistas individuales, o en el contexto de estas expresa la falta de voluntad de encontrarse con su contraparte en la mediación, esto no afecta el éxito de todo el programa. Así por ejemplo, el informe da cuenta del número de reuniones con el delincuente y las que se celebran con la víctima. No se espera que ningún acuerdo tenga un valor comparable al de la mediación civil y comercial.

En ese momento, de hecho, en general nos limitamos a predecir que la puesta a prueba implica la realización de una conducta destinada a eliminar las consecuencias nocivas o peligrosas derivadas del crimen, así como, cuando sea posible, la compensación por el daño causado por el mismo acusado.

Como es evidente, no se consideró adecuado extender el modelo de conciliación del proceso juvenil, aunque, por el contrario, sí se estimó necesario hacer que la probation estuviera sujeta a trabajos de utilidad pública. A este respecto, es importante subrayar que aunque la aprobación de la propuesta de prever esta institución -la probation- también en procesos penales contra adultos se ha definido como una revolución más cultural que legal ${ }^{26}$, se han planteado numerosas cuestiones de legitimidad constitucional, hasta el punto de considerar que el tratamiento relacionado con la suspensión del juicio con puesta en prueba tiene la naturaleza jurídica de castigo, o mejor dicho, de criptopena ${ }^{27}$.

En consecuencia, se puede formular una primera conclusión a este respecto: mientras que en el procedimiento para jóvenes el interés del acusado se coloca en el centro, en el de adultos

\footnotetext{
${ }^{25}$ La referencia es a la ley n. 67 del 28 de abril que, además de insertar un título V bis en el libro VI (relativo a procedimientos especiales) del código ritual, también introdujo el art. 168 bis, 168 ter y 168 quater en el Código Penal, que también permite a los adultos mayores de edad recurrir a la suspensión del juicio con puesta a prueba. Sobre este punto, ver BERTOLINI (2015), p. 25.

${ }^{26}$ PULPITO (2015), p. 98.

${ }^{27}$ Así SPANGHER (2015), p. 61. El Tribunal Constitucional se pronunció sobre la ratio y la función de la institución en estos términos: con el objetivo de contener la inflación criminal, en un intento de reducir la crisis de la sanción penal, haciendo posible recurrir a reacciones "apropiadas a la especificidad de los hechos ilícitos", en una concepción gradualística del crimen, avanzando hacia el objetivo de racionalizar y secularizar el sistema penal a través de la concentración de los recursos disponibles en los delitos más importantes, así como con una lectura realista del principio de obligatoriedad de la acción penal, con la conciencia de que el castigo puede no ser la única consecuencia inevitable de los delitos. De ahí la naturaleza innovadora de la prueba que marca una inversión de los sistemas de intervención tradicionales. Tribunal Constitucional, sentencia no. 91 de 27 de abril de 2018.
} 
es esencial que el acusado sea proactivo en la reparación de los daños y el trabajo de utilidad pública; sin embargo, parece prescindirse de las eventuales exigencias de la víctima ${ }^{28}$. Si nos detenemos a analizar la estructura del art. 464-bis c.p.p., surgen problemas críticos aún mayores. El programa de prueba que ya se ha mencionado, en cumplimiento de la disposición establecida en la letra c), debe explicar la conducta destinada a promover, cuando sea posible, la mediación con el ofendido ${ }^{29}$. Esta es la única referencia directa a la mediación, dado que, como ya se mencionó, los casos adicionales deben extraerse pacientemente de la diversa hojarasca legislativa. Sin embargo, también está claro que a lo largo de este camino podemos observar un evidente vulnus escatológico de la figura: el legislador proyecta la mediación en la disciplina procesal-penal, pero no se enfoca en especificar qué es y cómo debe llevarse a cabo. En última instancia, por tanto, es precisamente el juez y solo el juez el responsable de identificar lo que debe entenderse por mediación, así como el objetivo final que esta institución debe perseguir y eventualmente alcanzar. No puede dejar de subrayarse, por lo tanto, que tal disciplina se caracteriza actualmente por un preocupante vacío de objetivos, ya que no está claro, más allá de las peticiones de principios, cuál es el ubi consistam de la nueva figura, siempre que, por supuesto, no queramos contentarnos con una mediación que implique y se reduzca a la eliminación de las consecuencias dañinas o peligrosas derivadas del delito, así como -cuando sea posible- a la compensación por el daño causado por el mismo, como una interpretación sustancialmente abrogante de la letra c) en beneficio de las disposiciones contenidas en la letra b) de la disposición mencionada.

A pesar de su ambición de convertirse en una institución de justicia restaurativa dentro del sistema de justicia penal, la suspensión del juicio con libertad condicional otorga a la víctima un papel completamente evanescente, tanto en el debate sobre la admisibilidad de la solicitud como en el contenido del programa ${ }^{30}$. Respecto a lo primero, de hecho, la persona ofendida no tiene ningún poder de veto: el art. 464-quater c.p.p. prevé un mero deber de oír a la persona ofendida por parte del juez, antes de decidir sobre la solicitud ${ }^{31}$. El juez puede modificar el contenido del programa solo con el consentimiento del acusado y, posteriormente, con métodos no taxativos, puede prever prescripciones de comportamiento que se sitúen en una perspectiva reparadora hacia la víctima (la elusión o la atenuación de las consecuencias del delito, la posible indemnización por daños y perjuicios, la restitución); asimismo, el programa podrá imponer al imputado conductas encaminadas a promover, en lo posible, la mediación con el lesionado, sobre cuya viabilidad la UEPE realiza una averiguación previa, haciendo uso también a tal efecto de los centros o estructuras públicas o privadas presentes en el territorio (art. 141-ter disp. att. c.p.p.). La frase cuando sea posible, en una interpretación respetuosa con el papel central de la víctima -interlocutor necesario pero no vinculante del juez y de la U.E.P.E.- debe considerarse sintomática de la exclusión del ámbito de la mediación de aquellos "delitos sin víctima" que, entrando en el límite previsto en el art. 168-bis del Código Penal, son susceptibles de probation por expresa voluntad de la ley, pero no de mediación; por otro lado, la misma cláusula debe leerse en el sentido de subordinar la posibilidad de mediación a la voluntad real de la víctima, valorándose los esfuerzos unilaterales del delincuente en pro de la conciliación en otro sentido, por ejemplo, en el cálculo de la duración de la suspensión. Esta interpretación también se ajusta al contenido de la Directiva 2012/29 / UE, que textualmente prescribe que la mediación solo puede aplicarse cuando corresponda al interés de la víctima ${ }^{32}$. En general, por tanto, puede decirse que el papel del ofendido en la suspensión del juicio con libertad condicional está lejos

${ }^{28}$ Requisitos que, por ejemplo, trascienden la dimensión patrimonial, se enmarcan desde el perfil humano y interpersonal.

${ }^{29}$ Ver TONINI (2020), p. 824, que subraya cómo la prueba implica una serie de obligaciones para actuar. Por un lado, reparar, y por otro lado lograr la recuperación social de la persona.

${ }^{30}$ Asì MUZZICA (2019), pp. 9 y ss.

${ }^{31}$ Para una propuesta interpretativa orientada a potenciar la aportación cognitiva del ofendido en la fase de admisibilidad de la solicitud de libertad condicional, me remito a MUZZICA (2018a), pp. 173 y ss.

${ }^{32}$ Art. 12, ap. 1, segunda frase Directiva 2012/29/UE. 
de ser decisiva hasta el punto de considerar a la institución una concreción de los ideales de la justicia reparadora ${ }^{33}$.

La preferencia por una idea de justicia restaurativa centrada casi por completo en la eliminación del daño causado esencialmente desde el punto de vista patrimonial, se confirma en la nueva causa de extinción del delito por conducta restaurativa, de conformidad con el art. 162-ter del Código Penal, introducido por la Ley no. 103 de 23 de junio de 2017, que establece: En el caso de enjuiciamiento de una querella con posibilidad de perdón del ofendido, el juez declara la extinción del delito después de escuchar a las partes y al ofendido, siempre que el acusado haya reparado completamente, dentro de plazo máximo de la declaración de inicio del proceso de primera instancia, el daño causado por el delito, a través de la restitución o la indemnización, y haya eliminado las consecuencias dañosas o peligrosas del delito. La compensación por daños también puede reconocerse después de una oferta real en el sentido de los artículos 1208 y siguientes del código civil, formulada por el acusado y no aceptada por el ofendido, reconociendo el juez la idoneidad de la suma ofrecida para ese propósito ${ }^{34}$.

Por lo tanto, el legislador parece atribuir una vez más a la víctima un papel más bien marginal, considerando que al ofendido se le reconoce esencialmente el derecho de audiencia ${ }^{35}$ en el contexto de un procedimiento que parece estar dirigido a la declaración de extinción del delito, en lugar de a la satisfacción real de las necesidades de la víctima. Por otro lado, como prueba adicional de lo que se acaba de describir, es suficiente detenerse en el último inciso del nuevo art. 162-ter del código penal, en el que se hace referencia a la posibilidad de declarar el delito extinguido en presencia de una oferta -realizada de acuerdo con el art. 1208 del Código Civil italiano- que, aunque no fue aceptada por el ofendido, es considerada apropiada por el juez. Hay quienes vieron en esa norma una regla nociva con respecto a los propósitos de la justicia restaurativa, dado el valor exclusivo reconocido solo a la conducta unilateral del delincuente, de modo que un delito con víctima identificable y perjudicial para los intereses legales personales, puede extinguirse independientemente de la participación activa y directa del ofendido ${ }^{36}$.

Estas críticas surgieron especialmente después de una resolución en la que el juez de la audiencia preliminar del Tribunal de Turín ${ }^{37}$, en el contexto de procedimiento abreviado, cumpliendo stricto sensu las disposiciones reguladoras del art. 162-ter del Código Penal italiano, calificó como "justa" la oferta de un acusado de $1.500 €$ a pesar del rechazo del ofendido, y declaró extinguido el delito en cuestión. La respuesta del Estado -como en el ejemplo del juez del Tribunal de Turín- al aplicar el art. 162-ter c.p., ha comprometido la confianza de los ofendidos hasta el punto de considerar la conveniencia de una opción como la de no denunciar en absoluto, o incluso abandonar la querella ${ }^{38}$.

Este mecanismo introduce un nuevo desequilibrio de poder en una relación, la del delincuente y la persona ofendida, ya de por sí conflictiva, en clara antítesis con la finalidad de la justicia restaurativa, que es promover el empoderamiento de la víctima del delito: la norma, de hecho, impone al juez -en presencia de una oferta compensatoria congruente- neutralizar el disenso del ofendido que, si consiente, podría proceder a la tradicional remisión de la demanda. Sin embargo, esto no es compatible con los ideales de la justicia restaurativa, cuya razón de ser, aunque presente en las intenciones de la Comisión Fiorella ${ }^{39}$, estaba relacionada

\footnotetext{
${ }^{33}$ Sobre estas perplejidades, MUZZICA (2015), pp. 170 y ss.

34 Para más información sobre este punto, consúltese MURRO (2015), p. 40.

${ }^{35}$ Además, el decreto legislativo ni siquiera esclarece si el ofendido tiene un verdadero poder de oposición o simplemente expresa una opinión no vinculante para el juez. En el primer caso no es fácil entender si el "procedimiento de extinción" se detiene o si el juez se ve obligado a alguna forma procesal agravada como establecida en el art. 409 párrafo 2 del código penal tras la oposición a la solicitud de presentación de conformidad con el art. 410 del Código Penal.

${ }^{36}$ MUZZICA (2018b), pp. 22 y siguientes.

37 Tribunal de Turín, n. 1299 de 2 de octubre de 2017.

${ }^{38}$ Esta es la opinión crítica del abogado BONGIORNO (2017).

${ }^{39}$ Como se desprende del siguiente pasaje del Informe de la Comisión Fiorella (2013), p. 41: junto a el pago sustitutivo (oblazione), se propone también la introducción de una hipótesis general de extinción del delito en presencia de una conducta reparadora: este instrumento permite situar junto a la instancia deflacionaria el refuerzo de la idea de la llamada justicia reparadora, con la atribución al procedimiento de una función conciliadora entre el autor y la víctima del delito.
} 
con una formulación de la institución propuesta por la Comisión que no incluía la "variante secundaria" centrada en la oferta real, no aceptada por la persona ofendida ${ }^{40}$, lo que supone el verdadero punto de ruptura de cualquier posible vínculo entre el art. 162-ter c.p. y la justicia restaurativa.

La sensación suscitada en la opinión pública hizo predecible y apropiado un replanteamiento legislativo destinado a excluir de la aplicación del art. 162-ter del código penal el ilícito de los actos de persecución ${ }^{41}$. Con todo, estamos en presencia de una precipitada legislación que seguramente creará ulteriores problemas de aplicación de esta institución.

\section{La necesidad de una desjurisdiccionalización}

Por lo tanto, parece posible afirmar que el leit-motiv de las intervenciones legislativas más recientes está constituido por una tendencia a tomar decisiones de "desjurisdiccionalización" que, aunque enmarcadas dentro de la esfera de la justicia restaurativa, no siguen el camino de revalorización de la relación entre víctima y delincuente, que debería ser el núcleo duro de una mediación penal verdadera y efectiva.

En realidad, se podría hablar de una desjurisdiccionalización completamente sui generis, porque se lleva a cabo a través de una resolución judicial ${ }^{42}$, pero que, sin embargo, podría caer dentro del genus por el simple hecho de que es un instrumento que transmite la necesidad de jurisdicción para su cese rápido ${ }^{43}$, independientemente, como dijimos, de una efectiva revalorización de la posición de la víctima ${ }^{44}$. Por tanto, sería una fuga de la función principal de la jurisdicción penal, que es garantizar un enjuiciamiento respetando ciertas garantías esenciales para prevenir un proceso sobre la responsabilidad de un sujeto acusado de haber cometido un hecho ilícito. En un escenario semejante, la jurisdicción renegaría de sí misma, porque se "desinteresaría" de la responsabilidad penal para devenir una jurisdicción de "reparación". Y sin embargo, razonando en estos términos, una de dos: o la conducta ilícita se supone que daña ex se un bien jurídico digno de protección penal, y por lo tanto la intervención de la jurisdicción es necesaria para determinar la responsabilidad ${ }^{45}$, o bien la agresión del bien jurídico desde el principio no tiene la entidad como para provocar una respuesta penal del Estado (sería una extrema ratio) y, en consecuencia, el problema no está en la extinción del delito por conductas restaurativas, sino por la ausencia de relevancia penal de un conflicto que puede resolverse en una dimensión esencialmente compensatoria y, por consiguiente, a través del derecho civil.

Por otro lado, es bastante curioso afirmar que la sujeción a la pena de un hecho -ya es considerado penalmente reprochable si está tipificado como delito-esté condicionada por la no reparación del daño por parte del agente. Es decir, casi un reproche "de relato", podríamos decir. Estas construcciones alcanzan extremos de complejidad sistémica-¿quizás contradicciones?bastante preocupantes, y solo se pueden ver en el contexto de una despenalización torpe implementada a través de la desjurisdiccionalización, debiendo entenderse esta última, como se indicó, a modo de escape o sustracción de la jurisdicción de sus nobles propósitos primarios

\footnotetext{
40 PERINI (2017b), pp. 1274 y ss.

${ }^{41}$ Artículo 1, sección 2, de la Ley no. 172 de 2012 dispone que en el artículo 162-ter del Código Penal italiano se añade lo siguiente como último inciso: Las disposiciones de este artículo no se aplican en los casos a que se refiere el artículo 612-bis.

42 Disposición que, además, en el caso de la introducción de 163-ter del Código Penal italiano se caracteriza por un cierto grado de discreción subjetivista para la hipótesis en la cual la oferta, pese a ser aceptada por la víctima, es considerada apropiada por el juez.

${ }^{43}$ El prefijo transmite precisamente la idea de expulsión, sustracción, escape, en este caso aplicada a la función primaria de la justicia y el derecho penal.

${ }^{44}$ De hecho, la legislatura se mantiene fiel a ese enfoque patrimonial que ahora está en proceso de superación incluso en el lugar que representaba su templo sagrado, es decir, el código civil.

${ }^{45}$ De hecho, podría objetarse verdaderamente que se trata de casos punibles a instancia de parte y con respecto a los cuales, por tanto, el sistema legal valora la solicitud de castigo del individuo privado. Pero los planos no pueden superponerse: la eventual remisión de la demanda determina el resurgimiento de un obstáculo para el ejercicio de la acción penal. Por tanto, el delito existe (rectius podría existir), pero el sujeto pasivo (ya) no quiere que sea castigado (imputado); en el caso del nuevo art. 163-bis, por otro lado, es el crimen en sí mismo el que deja de existir (concretamente se extingue) y esto también de manera independiente y contraria a la voluntad de castigar a esa víctima, a la que el legislador también subordinó el enjuiciamiento del delito. Una verdadera contradicción en los términos, en cierto sentido.
} 
para la consecución de un objetivo de deflación más urgente. Es evidente que las instituciones analizadas aspiran a mejorar la efectividad ${ }^{46}$ del sistema de justicia, pero no su eficiencia ${ }^{47}$.

Volviendo, por tanto, al análisis de la compatibilidad de la mediación penal con nuestro sistema, no debemos olvidar que en Italia está el "problema" de la obligatoriedad de la acción penal.

De hecho, esa obligatoriedad podría representar un límite a los métodos restaurativos en la justicia penal, también a la mediación, no siendo el art. 112 de la Constitución (que prevé la obligatoriedad de la acción penal) el único obstáculo real. Aunque sea cierto que este principio es funcional para salvaguardar la igualdad de todos ante la ley, también es cierto que en materia de delitos que pueden ser sometidos a proceso a petición de una parte, una mediación previa a la denuncia de la notitia criminis, o destinada a lograr su revocación, ciertamente no viola el canon de la obligatoriedad de la acción penal ${ }^{48}$.

También en este caso, la mediación tendría el efecto de desprocesalizar, porque si pudiera evitarse incluso la presentación de la querella por el ofendido, se evitaría a la vez el inicio del proceso o, al menos, su enjuiciamiento normal hasta sentencia y, por tanto, se enmarcaría en la lista de mecanismos que modifican la secuencia normal de los actos del proceso penal antes de la decisión sobre la imputación ${ }^{49}$. Es evidente que el enjuiciamiento de oficio de algunos delitos (justamente aquellos en los que la mediación podría funcionar) sería un límite claro a cualquier forma de mediación penal concebida en este sentido.

Sin embargo, los principales problemas críticos surgen con respecto a la observación de que la mediación se usaría para poner al ofendido y al sospechoso en una relación dialógica en un momento en que dichas personas ni siquiera ostentan aún dicha condición. Este es, de hecho, un límite insuperable para la mediación penal, porque debería presuponerse la procesabilidad del sospechoso, lo que entraría en conflicto abiertamente con la presunción de inocencia prevista en el art. 27, párrafo 2 de nuestra Constitución y también en el art. 6 del CEDH y el art. 14 del Pacto Internacional de Derechos Civiles y Políticos ${ }^{50}$.

Además, si la mediación requiere la confesión previa del sujeto contra el cual se ha iniciado un procedimiento, se violaría el principio de nemo tenetur se detegere del art. 24, sección 2 , de nuestra Constitución ${ }^{51}$, que a su vez se basa en la presunción de inocencia, ya que sería contradictorio exigir una contribución cognitiva a la búsqueda de la verdad por quien supuestamente es ajeno al hecho por el cual se procede ${ }^{52}$.

En efecto, la Directiva condiciona el acceso a los servicios de justicia reparadora al reconocimiento de los hechos esenciales por parte del infractor, pero añade conscientemente que, cuando se trata de sospechosos o acusados, se preserva la presunción de inocencia (considerando 12), lo que sólo puede entenderse en los términos de la Recomendación de 1999, §14: la participación en la mediación (hoy, más correctamente, en un proceso de justicia reparadora) no debe utilizarse como prueba de la admisión de culpabilidad en el procedimiento

\footnotetext{
${ }^{46}$ Id est velocidad de definición.

${ }^{47}$ Es la protección ponderada de todos los intereses involucrados.

${ }^{48}$ Tribunal Constitucional, n. 88 de 15 febrero de 1991.

${ }^{49}$ Como MACRì (2011), pp. 25-26 ha propuesto correctamente, la mediación civil en casos de medical malpractice podría haber tenido efectos positivos también en el proceso penal, así como en el civil. Por tanto, sería suficiente que el legislador interviniera adecuadamente determinando los términos en los que se puede presentar una querella. De hecho, en casos de lesiones culpables, solo perseguibles a instancia de parte, los casos de definición consentida de la disputa se reducen drásticamente cuando la demanda ya ha sido propuesta. Por tanto, aumentar el plazo para proponer lo mismo (tal vez pasar de tres a seis meses, ya que, además, ya ha sucedido recientemente para algunos delitos) haría que el recurso a la mediación sea más efectivo, así como la previsión de causas de extinción del delito, si el procedimiento de mediación termina positivamente.

${ }^{50}$ De hecho, la práctica ha confirmado las críticas temidas casi de inmediato. A pesar del uso generalizado de este procedimiento alternativo (y de alguna manera revolucionario para una definición verdaderamente alternativa del proceso), se han planteado numerosas cuestiones de inconstitucionalidad de los artt. insertados por la ley n. 67/2014, para cuyo examen completo debe leerse a DELLA TORRE (2016), pp. 1-5 y ss. En particular, con la primera, en orden cronológico, el Tribunal de Grosseto ha señalado la cuestión de la inconstitucionalidad de las normas en cuestión, con referencia al art. 3, 111 sección 6, 25 párrafo 2 y 27 sección 2, ya que, de acuerdo con el sistema procesal y constitucional vigente, la imposición de la sanción penal establecida en el título ejecutivo provisional que ordena la prueba parecería basarse en la enunciación de una sentencia de culpa formulada explícita o implícitamente de manera ilógica y / o ficticia (Trib. Grosseto, ord. 10 de marzo de 2015, escritura de promoción n. 157).

${ }^{51}$ C. EDU, 17/12/1996, Saunders c. Reino Unido, par. 68.
}

52 UBERTIS (2004) p. 139. 
penal posterior. Esta condición no es exigida expresamente -como el mismo consentimiento de ambas partes- ni por el art. 29, apartado 4, de la Ley de Justicia Penal de Paz, que aunque parece asumir la Recomendación de 1999 con la prohibición absoluta de la uso a efectos de deliberación de las declaraciones de las partes durante la actividad de conciliación/mediación, ni en el contexto del probation procesal al que se refiere la citada Ley $67 / 2014$, ni en el contexto del art. 28 del Decreto Presidencial 448/88, que aunque no nombra la mediación, la evoca claramente en el apartado 2 .

A falta de indicaciones de la ley, y en ausencia de una asimilación de la reciente Directiva hasta ahora, en las interpretaciones de la doctrina y de los operadores del derecho sólo pueden existir conflictos sobre la compatibilidad del reconocimiento de esenciales hechos con la presunción de inocencia, así como con el principio conexo de nemo tenetur se detegere. Pero el contraste, de tono muchas veces ideológico, se reduce de hecho cuando se tiene en cuenta la fórmula prudente y equilibrada que utiliza la Directiva (para la que, repetimos, basta con el reconocimiento de los hechos esenciales del caso y, por tanto, no es necesaria la admisión de la culpabilidad [culpabilité/guilt]), pasando de las categorías lógico-lingüísticas desacuerdo en la creencia/desacuerdo en la actitud ${ }^{53}$, sólo esta última puede ser razonablemente objeto de una mediación aceptable para la parte ofendida, especialmente en la fase inicial del procedimiento. El "reconocimiento de los hechos esenciales" es, de hecho, muy distinto de la admisión plena de la culpabilidad (aunque siempre es posible $-y$, de hecho, no es raro- la libre elección del sospechoso/acusado), que, si se exige como condición indefectible de acceso, podría haber justificado las objeciones de garantía ${ }^{54}$. El acusado puede, y no debe, necesariamente mentir o callar, menos aún si se plantea la cuestión de un posible procedimiento de justicia restaurativa en un escenario de justicia leve ${ }^{55}$, que sólo puede funcionar si el acusado no queda atrapado en el tradicional juego defensivo, y puede al menos reconocer los hechos esenciales, tal y como se ha entendido anteriormente, $y$ se puede ayudar al ofendido a aceptar este reconocimiento como base de una confrontación constructiva: todo el camino parte necesariamente de esta disponibilidad recíproca inicial.

Por tanto, la mediación penal tiene un defecto de origen: la difícil relación con las garantías procesales ${ }^{56}$, incluso si las fuentes de conocimiento por parte de las autoridades judiciales de lo que sucedió durante la mediación fueran examinadas cuidadosamente, especialmente en el caso de un resultado negativo de la tentativa de mediación. Por ello, es imprescindible que la mediación penal cumpla con un estándar mínimo de protección, no solamente respecto de los derechos del reo y de la víctima, sino para que la mediación venga influenciada, más allá de la voluntariedad y la confidencialidad, por la neutralidad e imparcialidad del mediador, lo que equivale a reconocer la autonomía con respecto al proceso penal. Por lo tanto, la mediación, más que en reglas de procedimiento, debe basarse en principios deontológicos que hasta ahora no han sido objeto de un protocolo común, lo que impide el desarrollo homogéneo de mediación y de sus modalidades organizativas e institucionales ${ }^{57}$.

\footnotetext{
${ }^{53}$ CERETTI y MAZZUCATO (2001), pp. 772-776, para quien la fórmula del Consejo de Europa de 1999, "faits principaux de l'affaire/basic facts of the case" - casi coincidente con "faits essentiels de l'affaire/basic facts of the case" de la Directiva, aunque dirigida, como ya se ha destacado anteriormente, sólo al autor del delito - constituye un punto de equilibrio entre la inadmisibilidad de la confesión y la imposibilidad de una constatación judicial previa.

${ }^{54}$ Si la condición para el envío del mediador fuera la confesión, en caso de resultado negativo de la mediación, a la luz de una presunción de culpabilidad, y no de inocencia, podrían entonces operar tanto el fiscal como el juez -pero no el juez de la audiencia (ordinaria y de menores)- que, al no tener acceso al expediente, ex art. 431 c.p.p., ni a los actos de la mediación ni a su resultado negativo, no sabría nada, salvo que la defensa accediera a desclasificar toda esa información. En este sentido, ROSSI (2015), p. 3.

${ }^{55}$ La imagen de la mansedumbre es utilizada por ZAGREBELSKY (1992), p. 11 y ss. para indicar el sentido del carácter esencial del derecho de los Estados constitucionales actuales. Mansedumbre que se asocia naturalmente a los términos «coexistencia y compromiso.

${ }^{56}$ Ver KOSTORIS (2007) pp. 148 y ss.

${ }^{57}$ Así, CIAVOLA (2010), pp. 248 y ss.
} 


\section{Conclusiones}

Una de las principales dificultades que encuentra la justicia reparadora en su labor de penetración en los sistemas de justicia penal se refiere a la clasificación de las medidas reparadoras según las categorías sustantivas y procesales del derecho penal ${ }^{58}$.

La mediación y las medidas restaurativas conexas han encontrado su cuna natural en la fase ejecutiva, una vez establecida la responsabilidad penal del imputado, como modalidad de probation, experimentada en los sistemas anglosajones.

Sin embargo, puede decirse que -en general- tanto en los sistemas de persecución obligatoria como en los discrecionales, el lugar más natural para la adopción de medidas restaurativas debería ser el de la investigación, con la perspectiva de un sobreseimiento por remisión de la denuncia o por escaso o nulo interés público en el ejercicio del poder punitivo del Estado, cuando el autor haya demostrado efectivamente reparar el agravio causado con el delito.

No cabe duda de que, en esta línea, la solución adoptada en Italia con el juicio del imputado ofrece mayores garantías desde el punto de vista defensivo respecto a la diversion, porque esta institución presupone siempre un control judicial para que no se admitan compromisos restaurativos cuando no se dan las condiciones para proceder o cuando se pone de manifiesto la falta de fundamento del hecho o la extrañeza del imputado. Sin embargo, lamentablemente, la intervención legislativa no ha ido precedida de una preparación a la lógica y filosofía de la justicia restaurativa, y especialmente sin ninguna atención a las necesidades de protección e implicación de la víctima.

Es indudable que, en general, la reparación penal ha arraigado mejor en el sistema de justicia de menores que en el sistema penal de adultos: esta diferente evolución se explica por la mayor flexibilidad del instrumento penal juvenil y por una mayor voluntad cultural y psicológica (por parte de todos: víctimas, instituciones, opinión pública) de ofrecer al menor una oportunidad reparadora antes de infligirle una pena seca.

En el panorama europeo, la justicia restaurativa -incluso después de las buenas promesas iniciales- tiene dificultades para despegar y caracterizar el sistema de justicia penal en el que se introduce y, especialmente en los países de civil law, la resistencia depende del hecho de que la mediación es una forma de justicia empírica, en la que las soluciones dependen de un tratamiento "caso por caso" y de un elevado ejercicio de la discrecionalidad, especialmente en la apreciación de los resultados de la actividad restaurativa. Este enfoque no es fácilmente digerible para quienes están acostumbrados a una cultura jurídica opuesta, basada en los principios de la legislación general y el análisis meticuloso del caso.

En segundo lugar, la mediación "sacrifica" el texto de la ley -no la ley en sí misma- y lo sustituye por la centralidad de las partes y sus relaciones: el papel de la ley como ideal normativo abstracto es, por tanto, empujado a los márgenes por la justicia restaurativa para ser redescubierto y vivido más profundamente en la reconstrucción de las relaciones.

La mediación aborda en primer lugar las normas y valores compartidos en la comunidad, más allá del derecho positivo, ofrece poco espacio al simbolismo de la autoridad y favorece intervenciones muy informales que no son apreciadas por la tradición jurídica europea.

En muchos casos, la mediación, lejos de revelar las riquezas de una nueva comunicación entre las partes, ha demostrado ser un contexto ideal para las obras de manipulación en vista de los intereses de una sola parte: de hecho, las víctimas consideran la mediación como una especie de procedimiento subsidiario para tratar los casos de menor importancia en comparación con los que merecen la atención de la estructura judicial ordinaria. Se tiene la impresión de un sentimiento no del todo positivo, casi como si el paso a la mediación

${ }^{58}$ Para el análisis de estos problemas, véase MANNOZZI (2002), pp. 117-140. 
constituyera una especie de certificación de la menor importancia de la ofensa denunciada por la víctima ${ }^{59}$.

La historia y los resultados de la Comisión de la Verdad y la Reconciliación en Sudáfrica constituyen una aplicación consciente de los principios y criterios de la justicia reparadora ${ }^{60}$.

Por lo tanto, se cree que en el campo del derecho penal no se puede esperar un procedimiento de mediación completamente sustraído de la jurisdicción.

La mediación debería, en todo caso, ser conducida por más y más personal calificado y especializado para resolver la situación que surgió después de la comisión de un presunto crimen $^{61}$.

Sin embargo, no se puede pasar por alto que para algunos delitos el uso de la mediación es aún más problemático.

En el tema de la violencia de género, de hecho, se ha evidenciado el carácter crucial del tema de la formación: y es precisamente la ausencia de formación de los operadores de justicia, junto con la falta de disciplina orgánica, lo que obligó a la fiscalía de Tivoli ${ }^{62}$ a dictar las pautas para la aplicación de la ley no. 69 de 2019 (el llamado Código Rojo), relativa a la protección de las víctimas de la violencia doméstica y de género, y, en particular, en la directiva a la policía judicial n. 2 de 2019, y en definitiva a posicionarse seriamente sobre el asunto. En particular, se establece que si el primer acercamiento de la víctima tiene lugar en la escena de la violencia, la policía judicial debe, en cualquier caso, evitar cualquier intento de conciliar a la víctima y al agresor (punto 2.1., Letra f), y no intentar ninguna clase de mediación (punto 2.1., letra k). Lo que surge es una cierta cautela, si no desconfianza, por el uso de programas de justicia restaurativa en eventos "problemáticos", especialmente en presencia de una víctima particularmente vulnerable ${ }^{63}$. Esto nos lleva a preguntar, en un sentido crítico, si una perspectiva proteccionista tan rígida realmente esboza una tendencia paternalista excesiva del ordenamiento hacia la víctima ${ }^{64}$.

Aunque, de hecho, los resultados en el campo de la mediación civil dan una idea general de un aumento de tendencia en los casos en los que el instrumento logra su objetivo, es cierto que estos datos no autorizan automáticamente a considerar esta experiencia como sic et simpliciter permutable en derecho penal. El tipo de bienes jurídicos (opuestos) que entran en consideración y las dinámicas tan complejas (sobre todo en materia de garantías procesales) hacen que las dudas estén más que nunca justificadas sobre la creación de cualquier institución que abra la puerta a formas de mediación penal, a menos que esa apertura se asiente sobre la base de condiciones peculiares, compatibles con los fundamentos legales de nuestro sistema.

De hecho, en la actualidad, la mediación se presentaría como un elemento distorsionador adicional de un sistema procesal afectado por problemas ya serios de por sí, relacionados con

\footnotetext{
${ }^{59}$ Así, FORNASARI (2013), pp. 163 y ss. Exactamente en la dirección opuesta está el éxito indiscutible de las Comisiones de la Verdad y la Reconciliación creadas en muchos países para tratar las tragedias de época de las dictaduras y la delicada transición de los gobiernos autoritarios a las democracias parlamentarias. De Sudáfrica a Argentina, de Uruguay a Marruecos, la cuestión de los crímenes cometidos -en algunos casos incluso legalmente- por funcionarios y representantes del Estado, cuando no por estructuras especiales encargadas de la represión, ha sido abordada en un intento de privilegiar una mirada hacia el futuro y no hacia el pasado, con investigaciones y juicios sustraídos a la autoridad judicial en favor de instancias políticas. Se habla abiertamente, en este sentido, de justicia transicional. ${ }^{60}$ FLORES (1999), publicó uno de los primeros comentarios sobre la extraordinaria experiencia del trabajo de la Comisión presidida por Desmond Tutu. Sin embargo, es aconsejable leer directamente el Informe Final de la Comisión. Para una versión más accesible de la experiencia, léase TUTU (2001), pp. 115 y ss.

${ }^{61}$ En este sentido poseen autoridad las ideas que se extraen, también desde un punto de vista interdisciplinario, de COLAMUSSI (2011), pp. 270 y ss. En esa obra se explica cómo reflexionando sobre la probation en el procedimiento juvenil como símbolo de un apartamiento efectivo del sistema de justicia, las mismas ideas sirven de jure condendo para prefigurar un área autónoma de la mediación penal que se extendería también a los adultos.

62 Directrices de la Fiscalía de Tivoli, disponibles en gurisprudenzapenale.com.

${ }^{63}$ En este contexto se enmarca el Convenio del Consejo de Europa para prevenir y combatir la violencia contra las mujeres y la violencia doméstica, ratificado en Italia por la Ley 77/2013. Ahora está claro que el estado de sometimiento y opresión obtenido por el agresor violento se utilizaría, en el contexto de la mediación, para ejercer su poder incluso después de la presentación de la denuncia y, de hecho, fomentando la continuación de la intimidación y las represalias. Por esta razón, el Convenio prohíbe los métodos alternativos de resolución de conflictos -como la mediación y la conciliación- o las alternativas a las penas obligatorias. El propio concepto de mediación implica la voluntariedad en la búsqueda de una posición de equilibrio, por lo que se basa en el principio de igualdad de las partes. En la condición de sumisión psicológica que supone la violencia doméstica, no hay forma de encontrar ese equilibrio, por lo que nunca podría hablarse de un consentimiento libre y voluntario para la búsqueda de una posición mediana.

64 Sobre este punto, PARISI (2012), p. 12.
} 
elecciones desfavorables de política criminal que, por un lado, han desjurisdiccionalizado demasiado el proceso penal, y por otro lado anticipan el umbral del enjuiciamiento. Además, antes de rendirse ante el peso insostenible de la justicia penal, sería aconsejable proceder a una despenalización radical, franca y antipopulista, para actuar sobre las causas y no sobre los efectos simples de la ineficacia elefantiásica del funcionamiento del sistema de justicia. El legislador parece haberse dado cuenta recientemente de esta necesidad, como lo demuestra el art. 2 , sección 2 , de la ley delegada $n .67$ de 28 de abril de $2014^{65}$, implementado con los decretos delegados n. 7 y 8 de 15 de enero de 2016, publicados en G.U. 22 de enero (efectivo desde el 6 de febrero de 2016). Aunque la reforma ha sido aclamada por algunos como "histórica", y aunque este no es el lugar apropiado para proceder a un análisis detallado de las múltiples implicaciones que determinarán los cambios realizados ${ }^{66}$, sí puede decirse, como es tradición, que la reforma -al menos en parte- decepcionó las expectativas desde el punto de vista "cuantitativo" de la despenalización, dado que, al menos al nivel del Derecho sustantivo, por un lado son exiguos los delitos suprimidos, y por otro lado se ha introducido un sistema de sanciones -civiles y administrativas- que nunca había sido tan severo ${ }^{67}$, con el objetivo de desalentar a la comisión de nuevos delitos a través de la amenaza de un castigo ejemplarizante, aunque sea económico y no de libertate.

La reparación, a diferencia del castigo clásico, propone un camino apasionante que potencialmente tiene las cualidades para combinar la posibilidad del perdón con una promesa seria de un futuro diferente.

Volviendo al tema principal de la discusión, debería agregarse que podría ser útil, como lo demuestra la experiencia belga, crear formas de mediación post iudicium ${ }^{68}$ con el objetivo de mejorar el intercambio emocional entre los sujetos involucrados en el delito, a fin de suministrar un canal a través del cual satisfacer esas necesidades de comunicación con el delincuente que la víctima o sus familiares podrían percibir. A este respecto, se ofrecen puntos de reflexión desde el "Tavolo Tecnico n. 13", dedicado a la justicia restaurativa, a la protección de las víctimas y a la mediación penal, dentro de los Estados Generales de Ejecución Penal, que mejoran la fase de ejecución como terreno fértil para llevar a cabo caminos restaurativos, considerando, in primis, la inoperatividad in executivis de la presunción de inocencia ${ }^{69}$.

Siempre que las víctimas expresen su deseo al respecto, la disponibilidad del individuo ya reconocido por la jurisdicción como culpable para iniciar un proceso de comunicación controlado, puede ser extraordinariamente importante para ambas partes. De hecho, puede existir la posibilidad de expresar libremente sus sentimientos y ponerse a disposición para ofrecer aclaraciones sobre los hechos de una manera diferente a la que se ofreció en el tribunal. Por otro lado, por parte de la víctima puede existir la voluntad de tener respuestas a preguntas psicológicamente significativas sobre el delito o el delincuente, respuestas que, en la ritualidad litúrgica sagrada e inviolable del proceso, no se pueden obtener. Es significativo el ejemplo del caso relacionado con un asunto penal que había conmocionado a la opinión pública belga: el asesinato de dos novios en un estacionamiento. Aunque el proceso terminó con la condena del asesino, el padre de la joven víctima estaba extremadamente decepcionado con el juicio, ya que

\footnotetext{
${ }^{65}$ Lo que ha conferido una amplia delegación al Gobierno para la transformación de ciertos delitos en delitos administrativos y para la asunciòn de otros en la nueva y original figura del delito castigado con una sanción civil pecuniaria.

${ }^{66}$ Sin embargo, para un primer comentario sobre la reforma, ver GATTA (2016), pp. 1-3.

67 Que en algunos de sus perfiles también se podría sospechar de ilegitimidad constitucional por violación del principio de proporcionalidad y que, para las sentencias pendientes, podría generar problemas complejos de sucesión de leyes a lo largo del tiempo, subespecies de identificación y aplicación de la regla más favorable (ex art. 2. sección 4 del Código Penal italiano), por un lado, ya que el sujeto ante el cual se disputa el nuevo delito está "expropiado" de las garantías propias de la jurisdicción penal y, por otro lado, las sanciones (civiles o administrativas) a las que podría estar sujeto a menudo son muy grandes, mucho más aflictivas que las previstas por las normas penales.

${ }^{68} \mathrm{Algunas}$ iniciativas locales recientes, con la necesaria colaboración de las asociaciones, van en esta dirección. Recordemos, por ejemplo, el reciente anuncio publicado el 22 de septiembre de 2020 sobre la ejecución del proyecto "Caminos de la mediación penal" Oficina Interdistrital de Ejecución Penal Externa; o también el Acuerdo de Cooperación para actividades voluntarias de valor restaurativo entre la Oficina Interdistrital de Ejecución Penal Externa de Calabria en Catanzaro y la Cooperativa Social Malgrado Tutto - 12 de junio de 2020.

${ }^{69}$ Para un análisis más profundo, vid. Tabla 13 - Justicia restaurativa, mediación y protección de víctimas de delitos, en justice.it.
} 
no le proporcionó las respuestas necesarias para facilitar el proceso de duelo. A través de la acción de la asociación "Mediante", sin embargo, fue posible abrir un canal de comunicación entre el padre y el asesino, y los resultados fueron ciertamente positivos. Tranquilizados y sorprendidos de haber podido captar en la mirada del asesino un ápice de humanidad que no sospechaba, el hombre pudo decir que por supuesto, los sentimientos de odio y desprecio se han mantenido, pero al menos el deseo de venganza se ha desvanecido ${ }^{70}$.

El caso referido parece demostrar cómo a través de la creación de caminos de diálogo controlados entre los culpables y las víctimas, es posible facilitar el logro de esa reeducación que nuestra Carta fundamental designa como el principal fin al que deben tender las penas. El proceso de resocialización, de hecho, será extraordinariamente efectivo si el delincuente, habiendo adquirido conciencia del daño causado no solo desde un punto de vista económico, sino también y sobre todo desde un punto de vista humano, está disponible para hacer todo lo que esté a su alcance para aliviar el sufrimiento de la víctima.

En conclusión, in medio stat virtus, queriendo comprender en la necesidad de "mediar" también la elección de cuál es el modelo de mediación penal que queremos para nuestro ordenamiento, a partir de la insuperable premisa de que, a diferencia de lo sucedido e hipotetizado en materia de mediación civil, la mediación penal no debe ser vista como un instrumento de deflación procesal -porque, entendida de ese modo, acabaría sacrificando tanto las necesidades de la víctima como las del sospechoso/inculpado-, sino como un mecanismo de apoyo a la jurisdicción que debe ejercerse teniendo cada vez más en cuenta las necesidades reales y globales que deben protegerse en la práctica del "servicio" (porque ya no es sólo "poder") judicial.

\section{BIBLIOGRAFÍA CITADA}

AlLEGREZZA, SILVIA (2012): "La riscoperta della vittima nella giustizia penale europea", en: AA.VV., Lo scudo e la spada. Esigenze di protezione e poteri delle vittime nel processo pena-le tra Europa e Italia (Turín, Giappichelli), pp. 1-31.

BERTOLINI, BENEDETTA (2015): "La messa alla prova per adulti sotto le lenti della giustizia riparativa", en: Aprati, Roberta; La Regina, Katia y Marandola, Antonella (Eds.), Verso un processo penale accelerato: riflessioni intorno alla I. 67/2014, al D. Lgs. 28/2015 e al d.I. 2798/14 (Nápoles, collar de la Univ. La Sapienza-Dep. ciencias jurídicas), pp. 1-25.

BONGIORNO, GIULIA (2017): "La riforma Orlando indebolisce il reato, sanzione riparatoria applicabile nel 50\% dei casi", Disponible en: https://www.ilfattoquotidiano.it/2017/06/29/stalking-giuliabongiorno-la-riforma-orlando-indebolisce-il-reato-sanzione-riparatoria-applicabile-nel-50-deicasi/3696127/ [visitado el 3 de septiembre de 2018].

BUONATESTA, ANTONIO (2009): "Seminario "Territorial Network for the mediation in conflict", celebrado en Palermo el 26 de mayo de 2009". Disponible en: http://www.mediante.be/documentation/buonatesta_a_la_mediazione_nell_ambito_penale_in _belgio.pdf [visitado el 7 de septiembre de 2019].

CASSIBBA, FABIo SALVATORE (2017) “Le vittime di genere alla luce delle Convenzioni di Lanzarote e di Istanbul", en: Bargis, Marta y Belluta, Hervè (Eds.), Vittima di reato e sistema penale. La ricerca di nuovi equilibri (Turín, Giappichelli ), pp. 67-80.

CERETTI, Adolfo y MAZZUCATO, CLAUdia (2001): "Mediazione e giustizia riparativa tra Consiglio d'Europa e Nazioni Unite", en: Diritto penale e processo (No. 6), pp. 772-776.

CIAVola, AGATA (2010): Il contributo della giustizia consensuale e riparativa all'efficienza dei modelli di giurisdizione (Turín, Giappichelli).

\footnotetext{
$7^{70}$ El ejemplo es reportado por BUONATESTA, Director de la asociación "MEDIANTE" para Bélgica, durante el discurso presentado en el seminario "Territorial Network for the mediation in conflict", celebrado en Palermo el 26 de mayo de 2009. 
ColamusSI, MARILeNa (2011): La messa alla prova (Padua, Cedam).

CORNACCHIA, LUIGI (2013): "Vittime e giustizia criminale", en: Rivista italiana di diritto e procedura penale (No. 4), pp. 1764-1775.

DALIA, ANDREA ANTONIO (1982): "La deprocessualizzazione come obiettivo primario delle recenti modifiche al sistema penale", en: Rivista italiana di diritto e procedura penale (No. 10), pp. 491492.

Della TORRE, JACOPO (2016): “I dubbi sulla legittimità costituzionale del probation processuale: molteplici le ordinanze di rimessione alla Corte costituzionale". Disponible en: https://archiviodpc.dirittopenaleuomo.org/d/4466 [visitado el 25 de marzo de 2018].

EUSEBI, LUCIANO (2015): "La svolta riparativa del paradigma sanzionatorio. Vademecum per un'evoluzione necessaria", en: Mannozzi, Grazia y Lodigiani, Giovanni Angelo (Eds.), Giustizia riparativa. Ricostruire legami, ricostruire persone (Bolonia, II Mulino), pp. 97-118.

FLORES, MARCELLO (1999): Verità senza vendetta. L'esperienza della commissione sudafricana per la verità e la riconciliazione (Roma, Manifestolibri).

FoRNASARI, GABRIELE (2013): Giustizia di transizione e diritto penale (Turín, Giappichelli).

Gaito, Alfredo (2015): "L'adattamento del diritto interno alle fonti europee", en: AA.VV., Procedura penale, 4a edición (Turín, Giappichelli), pp. 33-53.

GATTA, GIAN LUIGI (2016): “Depenalizzazione e nuovi illeciti sottoposti a sanzioni pecuniarie civili: una riforma storica". Disponible en: https://archiviodpc.dirittopenaleuomo.org/d/4427 [visitado el 5 de abril de 2018].

KOSTORIS, ROBERTO E. (2007): Accertamento del fatto, alternative al processo, alternative nel processo (Milán, Giuffrè).

MACRì, FRANCESCO (2011): "Un campo provilegiato della mediazione penale: la responsabilità medica", en: Palazzo, Francesco y Bartoli, Roberto (Eds.), Mediazione penale nel diritto italiano e internazionale (Florencia, Firenze University Press) pp. 25-26.

MANNOZZI, Grazia (2002): "Collocazione sistematica e potenzialità deflattive della mediazione penale", en: De Francesco-Venafro (Ed.), Meritevolezza di pena e logiche deflattive (Turín, Giappichelli) pp. 117-140.

MANNOZZI, GRAZIA (2003): La giustizia senza spada. Uno studio comparato su giustizia riparativa e mediazione penale (Milán, Giuffrè).

Martelli, Stefania (2015) "Le convenzioni di Lanzarote e Istanbul: un quadro d'insieme", en: Luparia, Luca (Ed.), Lo statuto europeo delle vittime di reato. Modelli di tutela tra diritto dell'Unione e buone pratiche nazionali (Padua, Cedam), pp. 32-40.

MATTEVI, ELENA (2017): Una giustizia più riparativa. Mediazione e riparazione in materia penale (Nápoles, Editoriale Scientifica).

MURRO, OTTAVIA (2015): “Condotte riparatorie ed estinzione del reato: verso l'introduzione dell'art. 162-ter c.p.", en: Aprati, Roberta; La Regina, Katia y Marandola, Antonella (Eds.), Verso un processo penale accelerato: riflessioni intorno alla I. 67/2014, al D. Lgs. 28/2015 e al d.I. 2798/14 (Nápoles, Jovene), pp. 3-24.

MUZZICA, RAFFAELE (2015) “La sospensione del processo con messa alla prova per gli adulti: un primo passo verso un modello di giustizia riparativa?", en: Processo penale e giustizia (No. 3), pp. 158171

MuzzICA, RAFFAele (2018a): “La Consulta 'salva' la messa alla prova: I'onere di una interpretazione 'convenzionalmente' orientata per il giudice nazionale", Disponible en: https://archiviodpc.dirittopenaleuomo.org/d/6134 [visitado el 26 de junio de 2018]. 
MuzzICA, RAFFAele (2018b): “Sull'art. 162 ter c.p.: una norma dannosa per la Giustizia riparativa, inutile a fini deflattivi", en: Archivio penale (No. 1), pp. 1-26.

MuZzICA, RAFFAELE (2019): "Il ruolo della vittima negli istituti riparativi", en: Legislazione penale, pp. 9-31.

PARISI, FRANCESCO (2012): "Il diritto penale tra neutralità istituzionale e umanizzazione comunitaria". Disponible en: https://archiviodpc.dirittopenaleuomo.org/d/1868 [visitado el 12 de junio de 2018].

PARISI, FRANCESCO (2015): “I confini della restorative justice nella più recente normativa europea sulla tutela della vittima: ragionevole attuazione di una victim-centred justice o inevitabile condanna al destino di Sisifo?", en: Cortesi, Maria Francesca; La Rosa, Emanuele; Parlato, Lucia y Selvaggi, Nicola (Eds.), Sistema penale e tutela delle vittime tra diritto e giustizia (Milán, DIPLAP Editor), pp. 123-138.

PerinI, ChIARA (2017a) “Condotte riparatorie ed estinzione del reato ex art. 162 ter c.p.: deflazione senza Restorative Justice", en: Diritto penale e processo (No. 10), pp. 1274-1282.

PerINI, ChIARA (2017b): "L'alternativa al carcere al tempo della crisi: inveramento o deriva di sistema?", en: Spinellis, Calliope; Theodorakis, Nicholas; Billis, Emmanouil y Papadimitrakopoulos, George, Europe in Crisis: Crime, Criminal Justice, And The Way Forward. Essays in honour of Nestor Courakis (Atenas, Sakkoulas), volumen II, pp. 1858-1883.

PULPITO, LORENZO (2015): "Messa alla prova per adulti autonomia di un nuovo modello processuale", en: Processo penale e giustizia (№ 1), p. 97-110.

Relazione Commissione Fiorella (2013): “Delega al Governo per la riforma del sistema sanzionatorio", en: Dossier del Servizio Studi sull'A.S. (No. 110), pp. 1-66.

ReSTA, EligIO (1996): “Fiducia nella Giustizia”, en: Minori Giustizia (No. 10), pp. 68-71.

RIONDINO, MiCHele (2009): "Informe presentado en "First World Congress on Restorative Juvenile Justice" en Lima - Perú del 4 al 7 de noviembre de 2009”, en: Apollinaris (№ 1-2), pp. 447 -466.

RodRíGUez GARCíA, Nicolàs (1997): La justicia penal negociada. Experiencias de derecho comparado (Salamanca, Ediciones Universidad de Salamanca).

RosSI, GIOVANNI (2015): "La direttiva 2012/29/UE: vittima e giustizia riparativa nell'ordinamento penitenziario", en: Archivio penale (No. 2), pp. 508-533.

SCARDACCIONE, GILDA (1997): "Nuovi modelli di giustizia: giustizia riparativa e mediazione penale", en: Rassegna penitenziaria e criminoligica (No.1), pp. 10-20.

SECHI, PAOLA (2017): "Vittime di reato e processo penale: il contesto sovranazionale", en:Cassazione penale (№ 2, parte I y № 3, parte II), pp. 850-868.

SPANGHeR, GIORgIO (2008): Nuovo Trattato di Procedura Penale (Turín, Utet Giuridica), volumen IV. SPANGHER, GIORGIO (2015): Considerazioni sul processo "criminale" italiano (Turín, Giappichelli).

TONINI, PAOLO (2020): Manuale di procedura penale (Milán, Giuffrè).

TRANCHINA, GIOVANNI (2010): “La vittima del reato nel processo penale", en: Cassazione penale (№ 11), p. 4051B.

TUTU, DESMOND (2001): Non c'è futuro senza perdono (Milán, Feltrinelli).

UBERTIS, GIULIO (2004): Sistema di procedura penale: principi generali (Turín, Utet Giuridica).

ZAGREBELSKY, GuSTAVO (1992): Il diritto mite (Einaudi, Editorial). 
ZARA, GEORGIA (2018): “La psicologia della «vittima ideale» e della «vittima reale». Essere vittime e diventare vittime di reato", en: Rivista italiana di medicina legale e diritto sanitario (№ 2), pp. 615638.

\section{JURISPRUDENCIA CITADA}

Tribunal Constitucional, sentencia n. 88, de 15 de febrero de 1991, en Jur. Const.1990, 590.

C. EDU, de 17 de diciembre de 1996, Saunders c. Reino Unido, par. 68.

LA CORTE CONSTITUCIÓNAL, sentencia n. 272 de 23 de octubre de 2012.

TRIBUNAL DE CASACIÓN, sentencia n. 2301 presentada el 16 de enero de 2015.

Tribunal Grosseto, ord. 10 de marzo de 2015, TF, en DO, n. 35 de 2 de septiembre de 2015, escritura de promoción n. 157).

TRIBUNAL DE TURín, sentencia n. 1299 de 2 de octubre de 2017, GUP La Rosa.

TRIBUnAl Constitucional, sentencia no. 91 de 27 de abril de 2018.

\section{NORMAS JURÍDICAS CITADAS}

LEGGE № 104, Legge-quadro per l'assistenza, l'integrazione sociale e i diritti delle persone handicappate. Gazzetta Ufficiale № 39, 17 de febrero de 1992.

LEGGE № 479, Modifiche alle disposizioni sul procedimento davanti al tribunale in composizione monocratica e altre modifiche al codice di procedura penale. Modifiche al codice penale e all'ordinamento giudiziario. Disposizioni in materia di contenzioso civile pendente, di indennità spettanti al giudice di pace e di esercizio della professione forense. Gazzetta Ufficiale № 296, 18 de diciembre de 1999.

LEGGE COSTITUZIONALE № 2, Inserimento dei principi del giusto processo nell'articolo 111 della Costituzione. Gazzetta Ufficiale № 300, 23 de diciembre de 1999.

DECISIÓN MARCO 2001/220 / JAI DEL CONSEJO, de 15 de marzo de 2001, sobre la posición de la víctima en el proceso penal. Diario Oficial de la Unión Europea, № 82, 23 de marzo de 2001.

LEGGE № 134, Modifiche al codice di procedura penale in materia di applicazione della pena su richiesta delle parti. Gazzetta Ufficiale № 136, 14 de junio de 2003.

LEGGE № 38, Conversione in legge, con modificazioni, del decreto-legge 23 febbraio 2009, n. 11, recante misure urgenti in materia di sicurezza pubblica e di contrasto alla violenza sessuale, nonche' in tema di atti persecutori. Gazzetta Ufficiale № 95, 24 de abril de 2009.

LEGGE № 172 Ratifica ed esecuzione della Convenzione del Consiglio d’Europa per la protezione dei minori contro lo sfruttamento e l'abuso sessuale, fatta a Lanzarote il 25 ottobre 2007, nonché norme di adeguamento dell'ordinamento interno. Gazzetta Ufficiale № 235, 8 de octubre de 2012.

LEGGE № 119, Conversione in legge, con modificazioni, del decreto-legge 14 agosto 2013, n. 93, recante disposizioni urgenti in materia di sicurezza e per il contrasto della violenza di genere, nonche' in tema di protezione civile e di commissariamento delle province. Gazzetta Ufficiale № 242, 15 de octubre de 2013.

LEGGE № 67, Deleghe al Governo in materia di pene detentive non carcerarie e di riforma del sistema sanzionatorio. Disposizioni in materia di sospensione del procedimento con messa alla prova e nei confronti degli irreperibili. Gazzetta Ufficiale № 100, 2 de mayo de 2014. 
DeCRETo LegISLATIVo № 212, Attuazione della direttiva 2012/29/UE del Parlamento europeo e del Consiglio, del 25 ottobre 2012, che istituisce norme minime in materia di diritti, assistenza e protezione delle vittime di reato e che sostituisce la decisione quadro 2001/220/GAI. Gazzetta Ufficiale № 3, 5 de enero de 2016. 